\title{
Cyber Child Abuse in Bangladesh: A Rural Population-Based Study
}

\author{
Leuza Mubassara ${ }^{1}$, Muhammad Ibrahim Ibne Towhid ${ }^{2}$, Sarmin Sultana ${ }^{1, *}$, Asibul Islam Anik ${ }^{1}$, Marium Salwa ${ }^{1}$, Md. \\ Maruf Haque Khan ${ }^{1} \&$ M Atiqul Haque ${ }^{1}$ \\ ${ }^{1}$ Department of Public Health and Informatics, Bangabandhu Sheikh Mujib Medical University, Dhaka, Bangladesh \\ ${ }^{2}$ Center for Language Studies, University of Liberal Arts, Bangladesh \\ *Correspondence: Department of Public Health and Informatics, Bangabandhu Sheikh Mujib Medical University, \\ Dhaka-1000, Bangladesh. E-mail: sarmindoc@gmail.com
}

\author{
Received: November 21, $2020 \quad$ Accepted: January 19, $2020 \quad$ Online Published: January 20, 2021 \\ doi:10.5430/wjss.v8n1p104 URL: https://doi.org/10.5430/wjss.v8n1p104
}

\begin{abstract}
Background: Cyber abuse has become common among children worldwide; however, it is yet to receive attention in Bangladesh. The present study aimed to determine the prevalence and associated risk factors of cyber child abuse in the context of Bangladesh.

Methods: This population-based study was conducted on 460 children aged between 11 to 17 years recruited from a selected rural area of Bangladesh by simple random sampling. A cyber abuse scale was developed to measure the prevalence of cyber child abuse. Data were collected with a semi-structured questionnaire through face-to-face interviews.

Results: Around 33 percent of children were internet users. The prevalence of at least one, two, and three form(s) of cyber abuses was 59 percent, 38 percent, and 26 percent, respectively, among the internet users. The commonly reported abuses were being subjected to bullying, mockery, rumor, or humiliation (36\%), contacted anonymously with ill motive (29\%), receiving sexually explicit message or comment $(21 \%)$, and receiving sexually explicit picture or video (17\%). Male children were victimized more by different forms of cyber abuse. Logistic regression analysis showed that children whose internet using periods are more and who have higher knowledge about cyber abuse are more likely to be victimized with cyber abuse.

Conclusion: Cyber child abuse is a prevalent yet less explored public health threat in Bangladesh. Raising awareness against cyber abuse, educating children on prevention strategies, and imposing strict laws might help Bangladesh line up with the UN Convention on the Rights of the Child that the country signed in 1990.
\end{abstract}

Keywords: cyber abuse, children, prevalence, risk factors, Bangladesh

\section{Introduction}

The rapid growth of information and communication technologies (ICT) such as the internet and mobile phones during the last two decades has changed individuals', particularly young people's social interactions, learning strategies, and choice of entertainment (Mishna et al., 2009). According to the Global Digital Report (2020), 60 percent of the world population is connected to the internet, and approximately one in three children are regular internet users (United Nations Children's Fund [Unicef], 2017). Apart from its everyday uses in communication, education and entertainment, the internet concurrently serves as a potential platform for cyber abuse where children are more vulnerable to sexual and psychological abuse (Doornwaard et al., 2017).

Cyber abuse is an extension of the traditional form of abuse in internet platforms, where perpetrators can hide behind the screen, and it includes cyberbullying, cyberstalking, phishing, cyber sexual abuse, and hacking (Mishna, Cook, Saini, Wu, \& Macfadden, 2014). It can be defined as a willful and repetitive act of aggression via electronic communication devices which has adverse psychological consequences like depressive disorder, anxiety, low self-esteem, post-traumatic stress disorder, substance abuse, self-injury, and suicidal ideation (Samara et al., 2017; Çetin, Yaman and Peker, 2011).

Empirical studies worldwide revealed the prevalence of cyber abuse ranging from 10 to 35 percent (Agatston et al., 
2007). In a study from Sweden, Kloess et al. (2014) found that approximately 90 percent of children use the internet, and 32 percent of them are victims of cyber abuse. Studies conducted in Asian countries showed varied rates of cyber child abuse (CCA). A high prevalence of CCA in Asia was reported in China (70\%) and Singapore (58\%) (Rao, Bansal, \& Chandran, 2018). In the South Asian context, Rao et al. (2018) found 22 percent of Indian children faced cyber abuse.

Studies identified several risk factors for being victims of cyber abuse. Mishna et al.(2012) found that children adding strangers to their social media, using chat rooms, playing online games with strangers, and sharing passwords with friends were significant contributors to being a victim of cyber abuse. Field (2018) revealed that female children and children between 14 and 17 years were at a higher risk of becoming cyber victims.

Internet users in Bangladesh have increased exponentially with the introduction of high-speed internet connectivity across the country since 2013, bringing the total number of users to 10 million where a large number of these users are children (Hasnayen \& Sultana, 2016). A survey found that almost 32 percent of children in Bangladesh aged between 10 and 17 face cyberbullying and cyber harassment (UNICEF, 2019). Since CCA is a relatively new phenomenon and information is scarce in this regard in Bangladesh, we aimed to estimate the prevalence and risk factors of CCA among rural child internet users.

\section{Methods}

\subsection{Study Population}

This population-based cross-sectional study was conducted in an injury-based surveillance area at Raiganj Upazila (sub-district) of Sirajganj, a northwestern district of Bangladesh, and approximately $150 \mathrm{~km}$ away from Dhaka, the capital (Raigonj Upazila 2020). This surveillance area has been maintained by Centre for Injury Prevention and Research, Bangladesh (CIPRB), a research-based organization, since 2005.

In this surveillance area, every person and every household have an identification number. We prepared a list of children aged 11 to 17 years from the complete population-based list of this surveillance area. A total of 496 children were selected by a simple random sampling procedure from this list considering one child from one household. Finally, 460 children were interviewed from July 2019 to December 2019, with a 7.25 percent dropout.

The sample size was estimated based on a prevalence of 25 percent of internet users among children from a study conducted by UNICEF (The Daily Star, 2019); with a relative precision rate of 4 percent, a confidence level of 95 percent and considering 90 percent response rate, according to the methodology described by Lachenbruch, Lwanga and Lemeshow (1991).

A list of household addresses of all the selected children was prepared before data collection. Children over 11 years were chosen since they are considered to understand concepts, capable of elaborating their life situations and able to understand informed consent (Lindberg, Beaty, Juarez-Colunga, Wood, \& Runyan, 2015).

\subsection{Data Collection Tool}

A semi-structured questionnaire was used to collect data regarding the participant's socio-demographic characteristics, access to the internet, the pattern of internet use, knowledge regarding cyber abuse, and experience of the different forms of cyber abuse. Socio-demographic data included age, sex, educational level and marital status of the participants, and age, education level and occupation of the participants' parents. Further, data on participants' household assets such as table, chair, watch, computer, electricity supply, refrigerator, television, mobile phone, bicycle, and air conditioner were collected.

The internet use pattern was explored by asking if the participants were current or past internet users, daily internet users, and how many hours they spent on the internet in an average week. Participants who reported using the internet one month prior to the day of the interview, were considered as past users.

Participants' knowledge regarding cyber abuse was assessed through nine questions with yes/no response. The participants were asked if they were acquainted with the term 'cyber abuse', were aware of the existence of laws against cybercrime, and could correctly identify the different forms of cyber abuse. A knowledge score was prepared ranging from 0 to 9 , where every positive response to these questions was scored 1.

The experience of CCA was evaluated by a seven-item cyber abuse scale (CAS). The questions on the following abusive acts on the internet were asked to the respondents- being subject to bully, mockery, rumor or humiliation; contacted anonymously with an ill motive; personal photo, video or information shared without consent; personal 
photo or video edited by someone to ridicule; account hacked or logged without permission; received sexually explicit message or comment; and received sexually explicit picture or video.

All questions related to the different forms of cyber abuse consisted of multiple-choice answers: "once a week or more often (more than 50 times)", "several times a month (13-50 times)", "about once a month (6-12 times per year)", "several times a year (1-5 times)","not in the past year, but it has happened before", and "never in my life".

The abusive events of this tool were selected from reviewing relevant literature and finalized through consultative meetings with a group comprised of epidemiologist, criminologist, lawyer, and statistician. The reliability of the developed tool was checked and found reliable (Cronbach's alpha 0.642).

Pretesting of the CAS was done on four male and four female children at a school outside the surveillance area. Before data collection, necessary modifications were made based on the recommendations that came after pre-testing.

\subsection{Data Collection Procedure}

Children were interviewed face-to-face in an isolated place in their residents or any location convenient to them. In the case of ambiguity in understanding the language of any question, detailed clarification was given.

\subsection{Data Analysis}

Categorical variables were expressed in frequency and percentages while continuous variables in mean, standard deviation (SD) and median (inter quartile range, IQR). The wealth index was constructed based on household assets by principal component analysis (Filmer and Pritchett, 2001). The first factor of the principal component analysis was adopted to define relative socioeconomic status. Any of the abuses occurring in the previous year was counted as 1 , if 'once a week or more often' or 'several times a month' or 'about once a month' or 'several times a year' was checked.

We assessed the association between the independent variables and CCA (at least one form of CCA) in a binary logistic analysis with no abuse as a reference and reported the unadjusted odds ratios and p-values. Independent variables related to the socio-demographic characteristics and internet use that were assumed to have an influence on cyber abuse were further entered into a multiple regression model.

There was no evidence of multicollinearity following the diagnostic procedures other than ages of father and mother of the children (-.880). So, we included only father's age in the regression model. The inter-correlation coefficient with any of the other variables was found appropriate $(<-.273)$. Odds ratios (OR) were presented with a corresponding 95 percent CI. A p-value $<0.05$ was considered statistically significant. Data were analyzed using the Statistical Package for Social Sciences (version 22).

\subsection{Ethical Consideration}

Ethical approval for this study was obtained from the Institutional Review Board of BSMMU (2019/9214). Written consent was taken from the parents of the children, and finally, assent was obtained from the children. Both children and their parents were informed that there are questions related to violence. Parents were also informed that their children's partaking in this study was non-paid and voluntary. Participants' identities were kept confidential.

\section{Results}

Among the participants, 149 (32.4\%) children have reported of using the internet (past user $n=7$, current users $\mathrm{n}=142$ ). The majority of the internet users were male (63.1\%) and belonged to the 15 to 17 (75.2\%) year age group. About 20 percent of these participants used the internet daily (Table 1). In an average week, the median internet using time of the users was 3 (IQR, $0.5-90$ ) hours. The mean (SD) of the knowledge score of the children related to cyber abuse was $2.2(2.1)$. 
Table 1. Socio-demographic Characteristics of Child Internet Users ( $\mathrm{N}=149)$

\begin{tabular}{lll}
\hline Variables & Frequency & Percentage \\
\hline Sex $\quad 55$ & 36.9 \\
$\quad$ Male & 94 & 63.1 \\
Age (Years) & 37 & 24.8 \\
$12-14$ & 112 & 75.2 \\
$15-17$ & & \\
Education & 113 & 75.8 \\
$\quad$ Less than secondary & 36 & 24.2 \\
$\quad$ Secondary and above & 141 & 94.6 \\
Marital status & 8 & 5.4 \\
$\quad$ Unmarried & & \\
$\quad$ Married & 60 & 40.3 \\
Father's education & 89 & 59.7 \\
$\quad$ No formal education & & 35.6 \\
$\quad$ Having formal education & 53 & 64.4 \\
Mother's education & 96 & \\
$\quad$ No formal education & $45.9(7.8)$ & \\
Having formal education & $39.3(7.0)$ & 30.2 \\
Father's age, Mean (SD) & & 32.2 \\
Mother's age, Mean (SD) & 45 & 37.6 \\
Socio-economic status & 48 & 20.1 \\
$\quad$ Lower & 56 & \\
Middle & 30 & \\
Upper & &
\end{tabular}

$\mathrm{SD}$, standard deviation

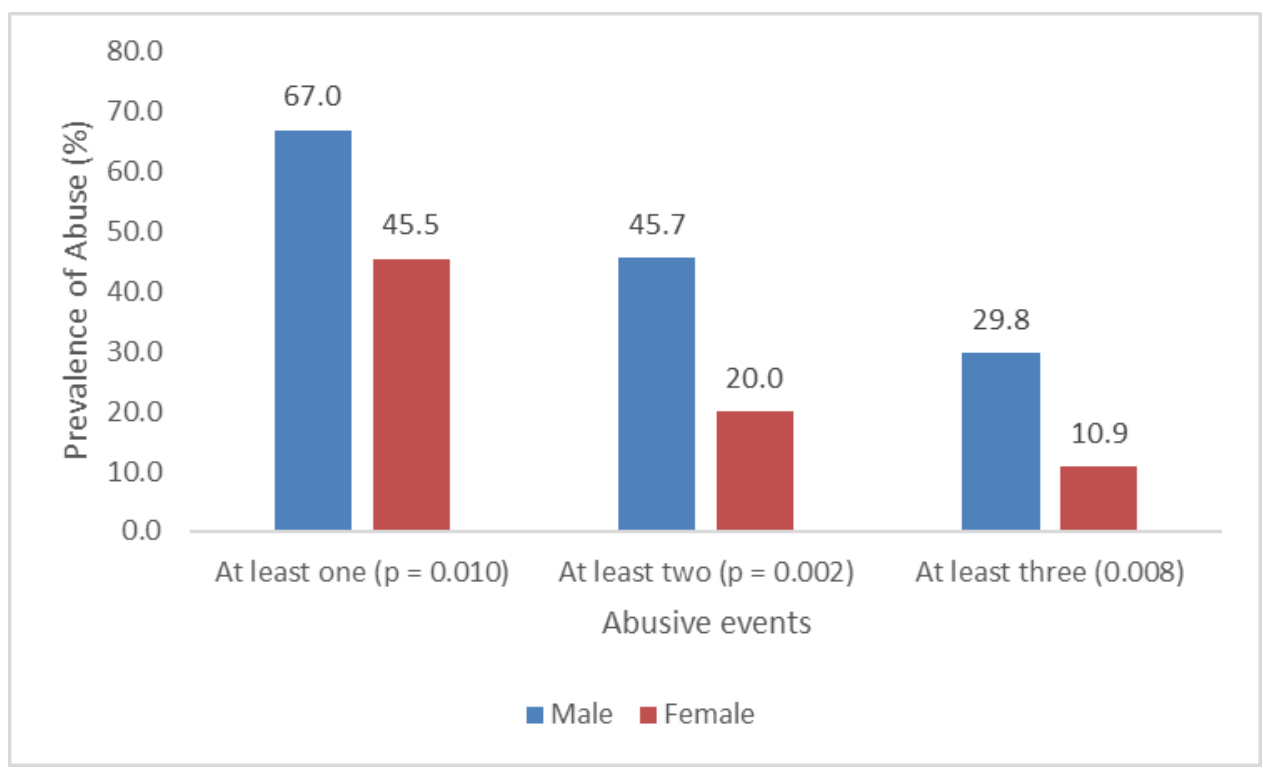

Figure 1. Prevalence of Cyber Abuse Among Child Internet Users (N=149)

As shown in figure 1, the prevalence rate of at least one form, at least two forms, and at least three forms of cyber abuse were 59 percent, 36 percent, and 23 percent, respectively. Male children were prone to face CCA more than their female counterparts (p-value $<0.05$ ) (Figure 1). 
Table 2. Prevalence of Different Types of Cyber Abuse Among Child Internet Users ( $N=149)$

\begin{tabular}{lllll}
\hline Abusive events & $\begin{array}{l}\text { Total } \\
\text { N (\%) }\end{array}$ & $\begin{array}{l}\text { Male } \\
\mathbf{n}(\mathbf{\%})\end{array}$ & $\begin{array}{l}\text { Female } \\
\mathbf{n}(\mathbf{\%})\end{array}$ & p-value \\
\hline Being subject to bully, mockery, rumor or humiliation & $54(36.2)$ & $42(44.7)$ & $12(21.8)$ & 0.01 \\
Contacted anonymously with ill motive & $43(28.9)$ & $33(35.1)$ & $10(18.2)$ & 0.02 \\
Received sexually explicit message or comment & $31(20.8)$ & $25(26.6)$ & $6(10.9)$ & 0.02 \\
Received sexually explicit picture or video & $25(16.8)$ & $21(22.3)$ & $4(7.3)$ & 0.01 \\
Personal photo, video or information shared without & $21(14.1)$ & $15(16.0)$ & $6(10.9)$ & 0.39 \\
consent & & & & 0.04 \\
Account hacked or logged without permission & $15(10.1)$ & $13(13.8)$ & $2(3.6)$ & 0.63 \\
Personal photo or video edited by someone to ridicule & $13(8.7)$ & $9(9.6)$ & $4(7.3)$ & \\
\hline
\end{tabular}

$\mathrm{n}(\%)$, Frequency with percentage

The most common forms of abusive events reported were being subject to bully, mockery, rumor, or humiliation (36\%), contacted anonymously with ill motive (29\%), while the least abusive events were having an account hacked or logged without permission $(10 \%)$ and personal photo or video edited by someone to ridicule (9\%). About 21 percent of children reported that they received sexually explicit messages, and 17 percent reported receiving video or pictures with sexual content. Most of these abusive events were significantly more prevalent among male children (p-value $<0.05$ ) (Table 2).

Table 3. Regression Analysis of Factors Associated with Cyber Abuse Among Child Internet Users ( $N=149)$

\begin{tabular}{|c|c|c|}
\hline Variables & Unadjusted OR (95\% CI) & Adjusted OR (95\% CI) \\
\hline \multicolumn{3}{|l|}{ Sex } \\
\hline \multicolumn{3}{|l|}{ Female } \\
\hline Male & $2.44(1.23-4.83) *$ & $0.65(0.27-1.57)$ \\
\hline \multicolumn{3}{|l|}{ Age (Years) } \\
\hline \multicolumn{3}{|l|}{$12-14$} \\
\hline $15-17$ & $2.36(1.11-5.03) *$ & $0.56(0.23-1.39)$ \\
\hline \multicolumn{3}{|l|}{ Education } \\
\hline \multicolumn{3}{|l|}{ Less than secondary } \\
\hline Secondary and above & $3.09(1.29-7.37) *$ & $0.62(0.22-1.73)$ \\
\hline \multicolumn{3}{|l|}{ Marital status } \\
\hline \multicolumn{3}{|l|}{ Unmarried } \\
\hline Married & $2.15(0.42-11.07)$ & $0.46(0.07-3.26)$ \\
\hline \multicolumn{3}{|l|}{ Father's education } \\
\hline \multicolumn{3}{|l|}{ No formal education } \\
\hline Having formal education & $0.59(0.29-1.16)$ & $0.95(0.41-2.19)$ \\
\hline \multicolumn{3}{|l|}{ Mother's education } \\
\hline \multicolumn{3}{|l|}{ No formal education } \\
\hline Having formal education & $0.49(0.24-0.99) *$ & $1.66(0.71-3.89)$ \\
\hline Father's age & $0.96(0.92-1.01)$ & $0.98(0.92-1.03)$ \\
\hline \multicolumn{3}{|l|}{ Socio-economic status } \\
\hline \multicolumn{3}{|l|}{ Lower } \\
\hline Middle & $0.70(0.30-1.63)$ & $0.92(0.35-2.4)$ \\
\hline Upper & $0.58(0.26-1.30)$ & $0.80(0.31-2.08)$ \\
\hline \multicolumn{3}{|l|}{ Weekly internet use } \\
\hline \multicolumn{3}{|l|}{$<3$ hours } \\
\hline$\geq 3$ hours & $3.04(1.54-6.01) *$ & $2.41(1.12-5.21) *$ \\
\hline Knowledge score for cyber abuse & $1.34(1.13-1.59) *$ & $1.27(1.05-1.53) *$ \\
\hline
\end{tabular}

Model summary: Cox \& Snell $R^{2}: 0.190$, Nagelkerke $\mathrm{R}^{2}: 0.256$

Level of significance: ${ }^{*}$-value $<0.05$ 
Unadjusted OR showed that child's sex, age, educational level, internet use time, knowledge score regarding cyber abuse, and mother's education were associated with being cyber abused. However, the adjusted model showed that higher duration of internet use and higher knowledge score were significantly associated with children being victim of cyber abuse. Children who used internet for $\geq 3$ hours in an average week reported to be abused 2.41 times more than the children who used internet for $<3$ hours (OR, 2.41; 95\% CI, 1.12- 5.21: p- value 0.025). The participants who had a higher knowledge score regarding cyber abuse were more likely to be abused (OR, 1.27; 95\% CI, 1.05-1.53; p-value0.014) (Table 3).

\section{Discussion}

Almost 60 percent of children using the internet faced at least one type of cyber abuse, and this rate was 19 percent among all children aged 11 to 17 years. Akareem \& Hossain (2016) also reported that one in every two children aged 12-18 years had reported of being abused online in Bangladesh. However, UNICEF (2019) reported a comparatively lower prevalence of 32 percent CCA among children aged 10 to 17 years in Bangladesh. The different rates of CCA were reported in studies conducted in other South Asian countries where the prevalence was 55 percent in Sri-Lanka (Suriyabandara, 2017), 53 percent in India (Cross Tab Marketing Services \& Telecommunications Research Group, 2012) and 22 percent in Pakistan (Munawar, Inam-ul-haq, Asad, Ali, \& Maqsood, 2014).

The comparison with reported epidemiological data on the prevalence of CCA elsewhere in the world is difficult since the methodologies used in these studies are not consistent. The wide range of prevalence reported in these studies is due to different case definitions for CCA, diverse populations, different modes of the interview, or different age groups for inclusion (Venkataraghavan, 2015).

The increasing internet and mobile penetration in recent days have made children vulnerable to cyber abuse worldwide, including in Bangladesh (Holloway, Green \& Livingstone, 2013). In a recent survey, it has been reported that the number of internet users increased from 0.1 to 80 million in Bangladesh over the last 18 years (Internet World Stats, 2020). This increasing number of users, especially among younger children, could lead them to be exposed to different types of cyber abuse in recent years (Holloway et al., 2013). According to the 'State of the World's Children 2017' report of UNICEF (2017), less than 5 percent of children under 15 years had internet access in Bangladesh. However, after two years of publishing this report, in 2019, we found 32.4 percent of rural children were internet users in the present study. This high rate of internet users increased the prevalence of CCA proportionately in the present study.

Being subject to bully, mockery, rumor, or humiliation through the internet was the most common form of CCA in this study which is consistent with another study by Hinduja \& Patchin (2010). Both studies revealed approximately one-third of the children faced mockery or were victims of rumor. Receiving a sexually explicit message or comment was found to be 21 percent in our study. A similar result was found in a study in Spain, where unwanted exposure to sexual content was 24 percent (Montiel, Carbonell \& Pereda, 2016). About 14 percent of internet users in our study reported that their personal photo/video/ information were shared without consent. This finding is consistent with the result of a study conducted in Lahore, Pakistan, where 18 percent of children reported similar experiences.

The present study found that more than 10 percent of the respondents' social media accounts were hacked or logged in without consent. A Chinese study also reported that 18 percent respondent's account was hacked, or access was blocked by stealing password (Zhou et al., 2013). In this study, different forms of abuse were more prevalent among male children. Popović-Ćitić et al. (2011) also reported that females are less likely to face abuse than males in cyberspace. Due to the traditional gender role, male children of Bangladesh get more access to the internet, while female children tend to deny or hide abusive events (Santisteban et al., 2018). This might explain the cause of the higher prevalence of CCA among male children in our study.

The present study showed that children who spend more time on the internet are at increased risk of experiencing CCA. In a UK-based study, the risk of cyber abuse was found more in children spending even a little over 120 minutes on social networking sites each day (Athanasiou et al., 2018). Studies also found that spending more time on the internet paves the way for posting more private information and meeting strangers online make children more vulnerable to cyber abuse (Mishna et al., 2012). Our study also found higher knowledge regarding cyber abuse as a predictive factor for CCA. However, the higher knowledge score might be attributable to their abuse experiences. Children who reported being a victim of cyber abuse are more likely to know about cyber abuse, the existence of law against cyber-crime, and different forms of abuses.

There are a few limitations to this study. We obtained CCA data by face-to-face interviews; hence there was no 
chance for cross-validation. Some questions on CCA were sensitive and were regarding private life, so some children might have avoided answering those questions. This was a cross-sectional study, so the temporal relation between cause and effect could not be established. As data were taken from a rural area, there is also a lack of generalization.

\section{Conclusion}

A substantial number of children of rural Bangladesh use the internet and experience cyber abuse. Male children have reported encountering different abusive events higher than females. Children who spend more time on the internet are often likely to be victims of cyber abuse. However, if the internet is used in the proper way, it has the potential to widen perspective and creativity among children. In this regard, children are needed to be kept at the center of the digital policies to ensure right to justice and protect them from the worst form of cyber outcome. Besides, the tech companies need to come up with specifications in their applications to protect children and young users. Further investigation is also necessary on CCA under diverse societal perspective to increase understanding of the dynamics, including the risk and protective factors of being cyber abused.

\section{Acknowledgements}

The authors are grateful towards Centre for Injury Prevention and Research, Bangladesh (CIPRB) for allowing to use their surveillance area for this study.

\section{References}

Agatston, P. W., Kowalski, R., \& Limber, S. (2007). Students' perspectives on cyberbullying. Journal of Adolescent Health, 41(6 SUPPL.), 59-60. https://doi.org/10.1016/j.jadohealth.2007.09.003

Akareem, H. S., \& Hossain, S. S. (2016). Determinants of education quality: what makes students' perception different?. Open Review of Educational Research, 3(1), 52-67. https://doi.org/10.1080/23265507.2016.1155167.

Athanasiou, K., Melegkovits, E., Andrie, E. K., Magoulas, C., Tzavara, C. K., Richardson, C., Greydanus, D., Tsolia, M., \& Tsitsika, A. K. (2018). Cross-national aspects of cyberbullying victimization among 14-17-year-old adolescents across seven European countries. BMC public health, 18(1), 800. https://doi.org/10.1186/s12889-018-5682-4.

Çetin, B., Yaman, E., \& Peker, A. (2011). Cyber victim and bullying scale: A study of validity and reliability. Computers \& Education, 57(4), 2261-2271. https://doi.org/10.1016/j.compedu.2011.06.014.

Cross Tab Marketing Services \& Telecommunications Research Group (2012). Online Bullying Among Youth 8-17 Years Old - Worldwide - Executive Summary Microsoft, pp. 1-2. Retrieved from https://www.microsoft.com/en-us/download/details.aspx?id=30148

Doornwaard, S. M., den Boer, F., Vanwesenbeeck, I., van Nijnatten, C., Ter Bogt, T., \& van den Eijnden, R. (2017). Dutch adolescents' motives, perceptions, and reflections toward sex-related internet use: Results of a web-based focus-group study. Journal of sex research, 54(8), 1038-1050. https://doi.org/10.1080/00224499.2016.1255873.

Field T (2018). Cyberbullying: A narrative review. Journal of Addiction Therapy and Research, 2: 10-27.

Filmer, D., \& Pritchett, L. H. (2001). Estimating Wealth Effects Without Expenditure Data-Or Tears: An Application To Educational Enrollments In States Of India. Demography, 38(1), 115-132. https://doi.org/10.1353/dem.2001.0003

Gámez-Guadix, M., De Santisteban, P., \& Alcazar, M. Á. (2018). The construction and psychometric properties of the questionnaire for online sexual solicitation and interaction of minors with adults. Sexual Abuse: Journal of Research and Treatment, 30(8), 975-991. https://doi.org/10.1177/1079063217724766

Global Digital Report (2020). Retrieved September 8, 2020, from https://datareportal.com/reports/digital-2020-global-digital-overview.

Hasnayen, E., \& Sultana, S. (2016). Internet use in Bangladesh: problems and prospects. Int. J. Comput. Sci. Inf. Technol. Res, 4(3), 251-260

Hinduja, S., \& Patchin, J. W. (2010). Bullying, cyberbullying, and suicide. Archives of Suicide Research, 14(3), 
206-221. https://doi.org/10.1080/13811118.2010.494133.

Holloway, D., Green, L., \& Livingstone, S. (2013). Zero to eight: Young children and their internet use. EU Kids Online, 36. https://doi.org/10.1186/1479-5868-10-137.

Internet World Stats, 2020. Retrieved September 20, 2020, from https://www.internetworldstats.com/asia.htm\#bd

Kloess, J., Beech, A., \& Harkins, L. (2014). Online child sexual exploitation: Prevalence, process, and offender characteristics. Trauma, violence \& abuse, 15, 126-139. https://doi.org/10.1177/1524838013511543.

Lachenbruch, P. A., Lwanga, S. K., \& Lemeshow, S. (1991). Sample Size Determination in Health Studies: A Practical Manual. Journal of the American Statistical Association, 1149. https://doi.org/10.2307/2290547.

Lindberg, D. M., Beaty, B., Juarez-Colunga, E., Wood, J. N., \& Runyan, D. K. (2015). Testing for abuse in children with sentinel injuries. Pediatrics, 136(5), 831-838. https://doi.org/10.1542/peds.2015-1487.

Mishna, F., Cook, C., Saini, M., Wu, M.-J., \& Macfadden, R. (2010). Interventions to prevent and reduce cyber abuse of youth: A systematic review. Research on Social Work Practice, 20. https://doi.org/10.1177/1049731509351988.

Mishna, F., Khoury-Kassabri, M., Gadalla, T., \& Daciuk, J. (2012). Risk factors for involvement in cyberbullying: Victims, bullies and bully-victims. Children and Youth Services Review, 34(1), 63-70. https://doi.org/10.1016/j.childyouth.2011.08.032.

Mishna, F., Saini, M., \& Solomon, S. (2009). Ongoing and online: Children and youth's perceptions of cyber $\begin{array}{lllll}\text { bullying. } \quad \text { Children } \quad \text { and } & \text { Youth Services }\end{array}$ https://doi.org/10.1016/j.childyouth.2009.05.004.

Montiel, I., Carbonell, E. \& Pereda, N. (2016). Multiple online victimization of Spanish adolescents: Results from a community sample. Child Abuse and Neglect, 52, 123-134. https://doi.org/10.1016/j.chiabu.2015.12.005.

Mukherjee, S., Sinha, D., De, A., Misra, R., Pal, A., \& Mondal, T. K. (2019). Cyberbullying among late adolescent: A cross-sectional study in two higher secondary schools of Kolkata, West Bengal. Indian J Public Health, 63(1), 86-88. https://doi.org/10.4103/ijph.IJPH_92_18

Munawar, R. Inam-ul-haq, Asad., M., Ali, S., \& Maqsood, H. (2014). Incidence, nature and impacts of cyber bullying on the social life of university students. World Applied Sciences Journal, 30, 827-830. https://doi.org/10.5829/idosi.wasj.2014.30.07.47

Popović-Ćitić, B., Djurić, S. \& Cvetković, V. (2011). The prevalence of cyberbullying among adolescents: A case study of middle schools in Serbia. School Psychology International, 32(4), 412-424. https://doi.org/10.1177/0143034311401700.

Raigonj Upazila (2020). $\quad$ Retrieved $\quad$ September $\quad 20, \quad 2020, \quad$ from http://raigonj.sirajganj.gov.bd/site/page/2e4de936-1ab0-11e7-8120-286ed488c766/\%E0\%A6\%AD\%E0\%A7\%8 C\%E0\%A6\%97\%Е0\%A6\%B2\%E0\%A6\%BF\%Е0\%A6\%95\%20\%Е0\%A6\%AA\%Е0\%A6\%B0\%Е0\%A6\%BF $\% \mathrm{E} 0 \% \mathrm{~A} 6 \% 9 \mathrm{~A} \% \mathrm{E} 0 \% \mathrm{~A} 6 \% \mathrm{BF} \% \mathrm{E} 0 \% \mathrm{~A} 6 \% \mathrm{~A} 4 \% \mathrm{E} 0 \% \mathrm{~A} 6 \% \mathrm{BF}$.

Rao, T. S., Bansal, D., \& Chandran, S. (2018). Cyberbullying: A virtual offense with real consequences. Indian Journal of Psychiatry, 60(1), 3-5. https://doi.org/10.4103/psychiatry.IndianJPsychiatry_147_18.

Samara, M., Burbidge, V., El Asam, A., Foody, M., Smith, P. K., \& Morsi, H. (2017). Bullying and cyberbullying: Their legal status and use in psychological assessment. International journal of environmental research and public health, 14(12), 1449. https://doi.org/10.3390/ijerph14121449.

Suriyabandara, V. S. (2017). An analysis of the attitude towards cyberbullying and cyber victimization among the university students of Sri Lanka. World Journal of Social Science, 4(2), 18. https://doi.org/10.5430/wjss.v4n2p18.

UNICEF (2017). State of the Worlds Children 2017 - Children in a Digital World, Unicef. Retrieved September 20, 2020, from https://www.unicef.org/publications/index_101992.html

UNICEF Survey (2019). Retrieved September 20, 2020, from https://www.unicef.org/bangladesh/en/press-releases/unicef-calls-concerted-action-prevent-bullying-and-harass ment-32-cent-children

Venkataraghavan, M. (2015). A study on the usage of mobile phones for cyber bullying among tweens \& teens of Chennai, India. Online Journal of Communication and Media Technologies, 19-30. 
Zhou, Z., Hanying, T., Tian, Y., Wei, H., Zhang, F., \& Morrison, C. (2013). Cyberbullying and its risk factors among Chinese high school students. School Psychology International, 34, 630-647. https://doi.org/10.1177/0143034313479692.

\section{Copyrights}

Copyright for this article is retained by the author(s), with first publication rights granted to the journal.

This is an open-access article distributed under the terms and conditions of the Creative Commons Attribution license (http://creativecommons.org/licenses/by/4.0/). 